University of Nebraska - Lincoln

DigitalCommons@University of Nebraska - Lincoln

USGS Staff -- Published Research

US Geological Survey

2014

\title{
Tissue-specific molecular immune response to lipopolysaccharide challenge in emaciated anadromous Arctic charr
}

Mathilakath Vijayan

University of Waterloo, matt.vijayan@ucalgary.ca

Anju Philip

University of Waterloo

Even Jørgensen

University of Tromsø

Alec Maule

USGS-BRD, Western Fisheries Research Center

Follow this and additional works at: http://digitalcommons.unl.edu/usgsstaffpub

Vijayan, Mathilakath; Philip, Anju; Jørgensen, Even; and Maule, Alec, "Tissue-specific molecular immune response to lipopolysaccharide challenge in emaciated anadromous Arctic charr" (2014). USGS Staff -- Published Research. 841. http://digitalcommons.unl.edu/usgsstaffpub/841

This Article is brought to you for free and open access by the US Geological Survey at DigitalCommons@University of Nebraska - Lincoln. It has been accepted for inclusion in USGS Staff -- Published Research by an authorized administrator of DigitalCommons@University of Nebraska - Lincoln. 


\title{
Tissue-specific molecular immune response to lipopolysaccharide challenge in emaciated anadromous Arctic charr
}

\author{
Anju M. Philip ${ }^{\text {a }}$, Even H. Jørgensen ${ }^{\mathrm{b}}$, Alec G. Maule ${ }^{\mathrm{c}}$, Mathilakath M. Vijayan ${ }^{\mathrm{a}, *}$ \\ ${ }^{a}$ Department of Biology, University of Waterloo, Waterloo, Ontario N2L 3G1, Canada \\ ${ }^{\mathrm{b}}$ Department of Arctic and Marine Biology, University of Tromsø, N-9037 Tromsø, Norway \\ ${ }^{\mathrm{c}}$ USGS-BRD, Western Fisheries Research Center, Columbia River Research Laboratory, Cook, WA 98605, USA
}

\section{A R T I C L E I N F O}

\section{Article history:}

Received 10 January 2014

Revised 18 February 2014

Accepted 19 February 2014

Available online 2 March 2014

\section{Keywords:}

Fish

Salvelinus alpinus

Cytokines

Serum amyloid protein A

Suppressors of cytokine signalling

SOCS

\begin{abstract}
A B S T R A C T
Anadromous Arctic charr (Salvelinus alpinus) undergo voluntary winter fasting for months in the Arctic. We tested the hypothesis that extended fasting will compromise the ability of this species to evoke an immune response. Charr were either fed or fasted for 85 days and challenged with lipopolysaccharide (LPS), and the molecular immune response in the liver and spleen assessed at 8 and $96 \mathrm{~h}$ post-injection. LPS increased IL-1 $\beta$, IL-8, and serum amyloid protein A (SAA) mRNA levels in both groups, but the liver IL$1 \beta$ and IL-8, and spleen IL- 8 responses were reduced in the fasted group. Fasting upregulated SOCS- 1 and SOCS-2 mRNA abundance, while LPS stimulated SOCS-3 mRNA abundance and this response was higher in the fasted liver. Collectively, extended fasting and emaciation does not curtail the capacity of charr to evoke an immune response, whereas upregulation of SOCS may be a key adaptation to conserve energy by restricting the inflammatory response.
\end{abstract}

(c) 2014 Elsevier Ltd. All rights reserved.

\section{Introduction}

It is well established that pro-inflammatory cytokines, including IL-1 $\beta$ and IL-8, are expressed in salmonids during the early phases of an infection, thereby initiating a strong innate inflammatory response (Sigh et al., 2004; Engelsma, 2002). While most studies in fish have examined the inflammatory response using immune cells, recent studies also alluded to immunostimulation of extra immune-related tissues, including red blood cells and hepatocytes (Morera et al., 2011; Philip et al., 2012). The liver plays an important role in intermediary metabolism and, therefore, may be particularly sensitive to changes in nutritional status of the animal. The liver is also a major site of acute phase proteins (APPs) synthesis, which is a key component of the innate immune response (SaranyaRevathy et al., 2012; Talbot et al., 2009). Serum amyloid protein A (SAA) is a major APP and an effector of innate immunity in all vertebrates, including fish (Steel and Whitehead, 1994; Talbot et al., 2009). Recently, we demonstrated that trout hepatocytes can mount an innate immune response to lipopolysaccharide (LPS) stimulation, suggesting a role for this tissue in the

\footnotetext{
* Corresponding author. Present address: Department of Biological Sciences, University of Calgary, 2500 University Drive N.W., Calgary AB T2N 1N4, Canada. Tel.: +1 (403)220 3094; fax: +1 (403)289 9311.

E-mail address: matt.vijayan@ucalgary.ca (M.M. Vijayan).
}

inflammatory response, including upregulation of IL-1 $\beta$, IL-8 and SAA (Philip et al., 2012).

Suppressors of cytokine signalling (SOCS) proteins are thought to play a key role in the modulation of cytokine signalling (Kile and Alexander, 2001). The negative regulation of cytokine signalling by SOCS involves activation of the JAK2-STAT5 pathway (O'Sullivan et al., 2011). Homologues of all the eight mammalian SOCS family members have been discovered in fish (Wang et al., 2011), while SOCS-1, SOCS-2 and SOCS-3 have been characterized in salmonids (Wang and Secombes, 2008). Although the functional significance of SOCS transcript abundance is unclear in fish, the mRNA abundance of SOCS-1-3 have been shown to be modulated by immunostimulants (Philip et al., 2012; Shepherd et al., 2012; Wang et al., 2011), but their expression with fasting is less clear.

Fasting leads to a negative energy balance and can restrict energy demanding pathways, including mounting an immune response (Berczi, 1986; Houston et al., 2007; Martin et al., 2010). Most studies that have examined the direct effects of nutritional status on the immune response have focused on mammalian models and showed a decreased capacity to defend against infection (Sun et al., 2001; Walrand et al., 2001). For instance, in mice and rat models, starvation reduces the number of $\mathrm{T}$ cells, suppresses the development of T-cell-mediated immunity, and induces apoptosis of lymphocytes, thereby impairing immune function (Wing et al., 1988; Pires et al., 2007). However, very little is known about the effect of dietary restriction on the immune response in fish. A 
recent study showed that in the Atlantic salmon (Salmo salar), starvation for 28 days led to a reduction in mRNA abundance of immune-related genes in the liver (Martin et al., 2010). Also, starvation for 31 days decreased the non-specific immune parameters, including haemagglutinating activity and respiratory burst activity in the sea bass (Dicentrarchus labrax) and blackspot sea bream (Pagellus bogaraveo) (Caruso et al., 2011). These studies suggest that fasting also compromises the molecular immune responses and function in teleosts as seen in mammalian models.

While reduced capacity for immune response activation in response to negative energy balance appears to be the norm in most animals (Martin et al., 2010; Berczi, 1986), those studies utilized animal models that do not naturally experience extended fasting. We asked the question whether animals exhibiting extreme adpatations, including extended fasting as part of a life-history strategy, show the same degree of immune response to immunostimulants as fed animals. To test this, we utilized the anadromous Arctic charr (Salvelinus alpinus), the northernmost freshwater fish and considered as the most cold-adapted species in the salmonid family (Siikavuopio et al., 2009). This species makes an annual seaward migration each spring where they exhibit concentrated bouts of heavy feeding before returning to freshwater every fall to overwinter. Overwintering is characterized by anorexia and energy substrate depletion leading to a continuous negative energy balance until they resume appetite again in May (Jørgensen et al., 1997). These seasonal patterns of appetite and growth are even exhibited by captive offspring of anadromous Arctic charr in spite of providing food in excess (Tveiten et al., 1996; Frøiland et al., 2010), making them an excellent model for mechanistic studies on the influence of nutritional status on immune function.

In the present study we tested the hypothesis that extended fasting will compromise the immune competence in a fish species which undergoes voluntary seasonal emaciation. This was carried out by comparing the molecular immune response in the liver, a metabolically active tissue, and spleen, a well established tissue model for immune studies (Stolte et al., 2008), in response to LPS (a well-established immunostimulant; Engelsma, 2002; MacKenzie et al., 2006; Fast et al., 2007) stimulation between fed and fasted anadromous Arctic charr. As markers of the inflammatory response, we measured the expression of pro-inflammatory cytokines IL-1 $\beta$ and IL-8 as well as the three isoforms of SOCS, SOCS-1, SOCS-2 and SOCS-3, while SAA was used as an indicator of the acute phase response.

\section{Materials and methods}

\subsection{Fish and experimental conditions}

The study was carried out at Tromsø Aquaculture Research Station $\left(69^{\circ} \mathrm{N}\right)$, Norway. Fish used were 3-year old, hatchery-reared offspring of wild, anadromous Arctic charr. The original broodstock was captured in Lake Vårflusjøen, Svalbard $\left(79^{\circ} \mathrm{N}\right)$ in 1990 . Eggs hatched in January 2008 and were held in fresh water at $6{ }^{\circ} \mathrm{C}$ under continuous light until July 2008 . The fry were then transferred to a circular, 3000-1 tank and held at ambient water temperature and natural photoperiod (transparent roof) until March 2010. Until then all fish were fed to satiety with commercial dry pellet (Skretting, Stavanger, Norway) using automatic disc feeders.

On March 9, a total of 68 fish were sorted out from the stock tank, anaesthetised in benzocaine $(50 \mathrm{ppm})$ and individually tagged (Floy FTF-69 fingerling tags, MGF, Seattle, USA). They were then randomly distributed among four 300-l tanks with ambient fresh water $\left(0.5^{\circ} \mathrm{C}\right)$ and held at a simulated, natural light regime $\left(69^{\circ} \mathrm{N}\right)$ and continuous feeding (Nutra Parr 2,0 mm; Skretting) until March 25. After the acclimation period, water temperature was elevated to $5^{\circ} \mathrm{C}$ and the fish in two tanks were deprived of food and those in the two other tanks were fed as before. This regimen was maintained until June 17, 2010, when the energy status of the fasted and fed fish (as evidented by their condition factor) were comparable to that of emaciated, wild charr in late winter and well-fed, wild charr in mid-summer, respectively (Jørgensen et al., 1997).

\subsection{Experimental design}

The experiment protocol used was approved by the Norwegian Committee on Ethics in Animal Experimentation. An initial sampling on June 17 ( 0 time) consisted of netting 10 fed and 10 fasted fish ( $n=5$ from each replicate tank) and euthanizing them with an overdose of benzocaine (150 ppm). Body mass (BM; g) and fork length $(\mathrm{FL} ; \mathrm{cm})$ were recorded and blood was collected from the caudal vein using heparinised vacutainers. The blood samples were held on ice until plasma was separated by centrifugation $(6000 \mathrm{~g}$, for $10 \mathrm{~min}$ ) and stored at $-20^{\circ} \mathrm{C}$ for glucose analysis later. The liver from each fish was excised and weighed before a small piece was removed and stored at $-20^{\circ} \mathrm{C}$ for glycogen analyses. Finally the rest of the carcass was frozen at $-20^{\circ} \mathrm{C}$ for later total fat analyses. $\mathrm{BM}, \mathrm{FL}$ and liver weight (LW) were used to calculate the condition factor $\left(\mathrm{CF} ; \mathrm{BM} / \mathrm{FL}^{3} \times 100\right)$ and hepatosomatic index (HSI; LW/ $\mathrm{BM} \times 100)$. Specific growth rate $(\mathrm{SGR})$ was calculated by the formula $\left[\left(\ln \mathrm{BM}_{T}-\ln \mathrm{BM}_{t} / T-t\right) \times 100\right]$ where $\mathrm{BM}_{\mathrm{T}}$ and $\mathrm{BM}_{\mathrm{t}}$ are the weights of the fish in June and March, respectively, and $T$ - $t$ the number of days between weight measurements.

On June 18 , the remaining fish (12 per tank) were injected (injection volume $2 \mathrm{ml} / \mathrm{kg}$ fish wt) with either LPS (Sigma L2630; $2.5 \mathrm{mg} / \mathrm{kg}$ fish wt in PBS) in one tank each for fed and fasted groups] or the vehicle (PBS; Sigma P5493). The fish were euthanized at 8 and $96 \mathrm{~h}$ post-injection ( $n=6$ for each time-point) as described above, after which pieces of the liver and spleen were excised and stored in RNAlater, first at $4{ }^{\circ} \mathrm{C}$ for $24 \mathrm{~h}$, and then at $-80^{\circ} \mathrm{C}$ until measuring transcript levels later.

\subsection{Analyses}

Plasma glucose was determined by a Randox GL 1611glucose kit (RANDOX Laboratories Ltd., Crumlin, UK). The same kit was used to determine liver glycogen content by analysing liver glucose content before and after amyloglucosidase hydrolysis (Keppler and Decker, 1974). Liver protein content was analysed using bicinchoninic acid Protein Assay Reagent Kit (Pierce \# 23227; Pierce Chemical Company, Rockford, Illinois) using bovine serum albumin as the standard. Total body fat was extracted by petroleum benzine (Merck, Darmstadt, Germany) in a Behrotest extraction system (Behr Labor-technik, Düsseldorf, Germany) according to a protocol described before (Frøiland et al., 2010). Plasma cortisol levels were analysed in diethyl ether extracted plasma by radioimmunoassay and validated for Arctic charr as described previously (Tveiten et al., 2010).

\subsection{Quantitative real-time PCR ( $q P C R$ )}

\subsubsection{RNA extraction and cDNA synthesis}

Total RNA was extracted from liver and spleen tissue using the RNeasyextraction kit (Qiagen, Mississauga, ON, CAN) and treated with DNase. The concentration of total RNA was determined spectrophotometrically at $260 / 280 \mathrm{~nm}$ using a NanoDrop ${ }^{\mathrm{TM}}$ spectrophotometer (Thermo Scientific, Napean, ON, CAN). First-strand cDNA was synthesized from $1 \mu \mathrm{g}$ of total RNA using the High capacity cDNA reverse transcription kit (Applied Biosystems, CA, USA) according to the manufacturer's instructions. 


\subsubsection{Quantification}

Samples were quantified using a SYBR green fluorescent dye master mix in an iCycler real-time PCR detection system (BioRad, Hercules, CA, USA). The genes of interest were IL-1 $\beta$, IL-8, SAA, SOCS-1, SOCS-2 and SOCS-3, while elongation factor 1 alpha (EF1 $\alpha$ ) was the housekeeping gene. Primer pairs (Table 1) for these genes were designed from rainbow trout cDNA sequences using Primer 3 version 0.4 . software. Threshold cycle values for each sample were calculated using iCycler iQ real-time detection software (Bio-Rad). Briefly, each sample was assayed in triplicate. A master mix containing $2.5 \mu \mathrm{L}$ cDNA, $2.5 \mu \mathrm{L}$ of primer pair ( $10 \mathrm{mM}$ each of the respective forward and reverse primers), $40 \mu \mathrm{L}$ of SYBR green mix and $35 \mu \mathrm{L}$ of nuclease-free water was prepared for each sample, after which $25 \mu \mathrm{L}$ was added to each of three wells. Each sample was assayed for the genes of interest and the housekeeping gene. The following PCR conditions were used for amplification: $95^{\circ} \mathrm{C}$ for $3 \mathrm{~min} ; 40$ cycles of $95^{\circ} \mathrm{C}$ for $20 \mathrm{~s}$ and annealing temperature (see Table 1) for $20 \mathrm{~s}$; $95^{\circ} \mathrm{C}$ for $1 \mathrm{~min} ; 55^{\circ} \mathrm{C}$ for $1 \mathrm{~min}$ followed by melt curve analysis to confirm the presence of a single amplicon, starting at $55^{\circ} \mathrm{C}$ and increasing in $0.5{ }^{\circ} \mathrm{C}$ increments to $95^{\circ} \mathrm{C}$ every $10 \mathrm{~s}$. Copy number of transcripts for each gene was determined with the threshold cycles (CT) using plasmid standard curves exactly as described before (Aluru et al., 2010). EF1 $\alpha$ was used as the housekeeping gene for normalization as this transcript level remained unchanged between treatment groups. Briefly, standard curves were generated using a serial dilution of plasmid vector stock (pGEM-Teasy cloning vector; Promega,Valencia, CA, USA) with inserted target sequences to attain varying copy number of insert sequences $\left(3 \times 10^{10}\right.$ $3 \times 10^{1}$ copies). PCRs were performed as described above with $2.5 \mu \mathrm{L}$ of the different plasmid dilutions added as template. Background subtracted CT values were plotted against log of standard copy numbers to obtain standard curves.

\subsection{Statistical analysis}

Data are shown as mean \pm standard error of mean (SEM). Outliers, values that were two standard deviations above or below the mean, were omitted from the analyses. Three-way ANOVA followed by Holm Sidak's post hoc was used to compare the effect of different treatments on mRNA levels. The units for mRNA levels for each gene are copy numbers for that particular gene obtained from the standard curve and then normalised to EF1alpha. These numbers were used for statistical analysis although percentages are shown in the Figures. Student $t$-test was used to compare the effect of different treatments on body mass, condition factor,
SGR, HSI, body fat, liver glycogen and plasma glucose and cortisol levels. The data were transformed, wherever necessary, for homogeneity of variance, but non-transformed values are shown in the figures. A probability level of $P<0.05$ was considered significant. Statistical analyses were performed with SigmaStat (Systat Software Inc., San Jose, CA, USA).

\section{Results}

\subsection{Body mass, specific growth rate, condition factor and fat content}

As evidenced by the fish sampled at 0 time, long-term fasting significantly reduced body mass, specific growth rate, condition factor and body fat content in anadromous Arctic charr. The mean body mass of fasted charr was reduced by $\sim 60 \%$, this was also reflected in significant differences in SGR (Table 2). The body fat content was $\sim 88 \%$ lower in the fasted charr, and the condition factor was also reduced in the fasted charr by $\sim 38 \%$ compared to the fed charr (Table 2). The mean body mass and condition factor of the fish used for the immune challenge were similar to those of the fish sampled at 0 time, being $327 \pm 24.5 \mathrm{~g}$ and $1.17 \pm 0.03$, respectively, in fed fish and $128 \pm 5.3 \mathrm{~g}$ and $0.75 \pm 0.01$, respectively, in fasted fish.

\subsection{HSI, liver glycogen content and plasma glucose and cortisol levels}

The HSI ( $\sim 88 \%)$ and liver glycogen content $(\sim 88 \%)$ were significantly reduced by fasting compared to the fed charr (Table 2). There were no significant differences in either plasma glucose or cortisol levels between the fed and fasted charr (Table 2).

\subsection{Gene expression}

\subsubsection{Cytokine expression}

LPS stimulation increased IL-1 $\beta$ and IL- 8 mRNA abundances in the liver and spleen of both fed and fasted Arctic charr. In fed charr, IL-1 $\beta$ (66-fold increase in the liver; 68 -fold increase in the spleen) and IL-8 (21-fold increase in the liver; 35-fold increase in the spleen) expression levels peaked at $8 \mathrm{~h}$ post-LPS injection and returned to control levels by $96 \mathrm{~h}$ in both tissues examined (Fig. 1A-D). However, tissue-specific temporal differences in cytokine mRNA levels were observed in the fasted charr; IL- $1 \beta$ and IL- 8 expression levels, which peaked at $8 \mathrm{~h}$ post-LPS injection, failed to return to control levels by $96 \mathrm{~h}$ in the liver, but did so in the spleen of fasted charr (Fig. 1A-D). Moreover, there was a temporal increase in liver IL-8 levels in the control fed group at $96 \mathrm{~h}$

Table 1

Gene-specific primers for quantitative real-time PCR

\begin{tabular}{|c|c|c|c|}
\hline Gene ID & Primer sequences $\left(5^{\prime}-3^{\prime}\right)$ & Temp $\left({ }^{\circ} \mathrm{C}\right)$ & Amplicon size (bp) \\
\hline \multirow[t]{2}{*}{ IL-1 $\beta$} & Fwd: GGAGAGGTTAAAGGGTGGCGA & 60 & 121 \\
\hline & Rev: TGCCGACTCCAACTCCAACA & & \\
\hline \multirow[t]{2}{*}{ IL-8 } & Fwd: CACTGAGATCATTGCCACTCTGA & 60 & 81 \\
\hline & Rev: ATGACCCTCTTGACCCACGG & & \\
\hline \multirow[t]{2}{*}{ SAA } & Fwd: TTGTTCTGACCCTCGTTGTAGGAGC & 60 & 101 \\
\hline & Rev: CATGTCGCCATATGCACGCC & & \\
\hline \multirow[t]{2}{*}{ SOCS-1 } & Fwd: TCAGCGTACGCATCGTCTAT & 55.7 & 120 \\
\hline & Rev: CGGTCAGGCTTTTCTTAGAGG & & \\
\hline \multirow[t]{2}{*}{ SOCS-2 } & Fwd: TCGGATGACTTTTGGCCTAC & 60 & 102 \\
\hline & Rev: CCGTTCTTCTCTCGTTTTCG & & \\
\hline \multirow[t]{2}{*}{ SOCS-3 } & Fwd: GAACAACACAAGATATCAAGCTCAAGG & 65.7 & 351 \\
\hline & Rev: GAAGGTCTTGTAACGGTGAGGCAG & & \\
\hline \multirow[t]{2}{*}{$\mathrm{EF} 1 \alpha$} & Fwd: CATTGACAAGAGAACCATTGA & 56 & 95 \\
\hline & Rev: CCTTCAGCTTGTCCAGCAC & & \\
\hline
\end{tabular}

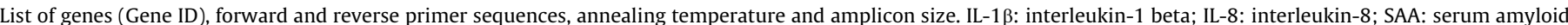
protein A; SOCS: suppressors of cytokine signalling; EF1 $\alpha$ : elongation factor $1 \alpha$. 
Table 2

Biometrical measurements and metabolic and stress parameters.

\begin{tabular}{lcc}
\hline Biometrical measurements & $\begin{array}{l}\text { FED } \\
(n=7)\end{array}$ & $\begin{array}{l}\text { FASTED } \\
(n=10)\end{array}$ \\
\hline BM $(\mathrm{g})$ & $339 \pm 52^{\mathrm{a}}$ & $138 \pm 7.5^{\mathrm{b}}$ \\
CF & $1.20 \pm 0.06^{\mathrm{a}}$ & $0.75 \pm 0.01^{\mathrm{b}}$ \\
SGR & $0.79 \pm 0.08^{\mathrm{a}}$ & $-0.17 \pm 0.01^{\mathrm{b}}$ \\
Body fat $(\%)$ & $10.4 \pm 1.5^{\mathrm{a}}$ & $1.25 \pm 0.38^{\mathrm{b}}$ \\
HSI & $1.96 \pm 0.12^{\mathrm{a}}$ & $1.03 \pm 0.04^{\mathrm{b}}$ \\
Metabolic and stress parameters & & \\
Liver glycogen $(\mu \mathrm{mol} / \mathrm{g}$ protein) & $1408 \pm 182^{\mathrm{a}}$ & $168 \pm 42^{\mathrm{b}}$ \\
Plasma glucose $(\mathrm{mM})$ & $4.27 \pm 0.17^{\mathrm{a}}$ & $4.25 \pm 0.23^{\mathrm{a}}$ \\
Plasma cortisol $(\mathrm{ng} / \mathrm{ml})$ & $16.5 \pm 4.8^{\mathrm{a}}$ & $16.8 \pm 5.4^{\mathrm{a}}$
\end{tabular}

The table provides the body mass (BM), condition factor (CF), specific growth rate (SGR), body fat content, hepatosomatic index (HSI), liver glycogen content and plasma glucose and cortisol levels in the fed and fasted charr sampled at time 0 prior to lipopolysaccharide treatment. Different letters denote significant difference. All values represent means \pm SEM ( $n$ denotes the number of fish) ( $t$ test; $P<0.05)$.

post-injection. Overall, fasted charr showed significantly lower mRNA levels of IL-8 in both tissues compared to fed charr. IL-1 $\beta$ was significantly reduced in the liver but not the spleen of fasted charr compared to fed charr.

\subsubsection{SAA expression}

LPS injection increased SAA transcript levels in the liver and spleen of both fed and fasted Arctic charr. In the liver of both fed and fasted charr, SAA mRNA levels peaked at $96 \mathrm{~h}$ post-LPS injection (34-fold increase for fed charr; 74-fold increase for fasted charr) with no significant change at $8 \mathrm{~h}$ post-injection compared to the controls (Fig. 2A). Fasted charr showed the same overall level of SAA mRNA abundance as fed charr. There was a temporal increase in liver SAA levels in the control fasted fish at $96 \mathrm{~h}$ postinjection. An interaction between nutritional status and time post-LPS injection was observed in the spleen. In the spleen of fed charr, SAA levels peaked at $96 \mathrm{~h}$ post-LPS injection (134-fold) with no significant change at $8 \mathrm{~h}$, while in the spleen of fasted charr, SAA expression was significantly higher at both $8 \mathrm{~h}$ (24-fold) and $96 \mathrm{~h}$ (71-fold) post-LPS injection compared to the control groups (Fig. 2B).

\subsubsection{SOCS expression}

In general, fasted charr, irrespective of LPS/PBS injection upregulated the overall mRNA abundances of the three SOCS isoforms in a tissue-specific manner (Figs. 3-5). SOCS-2 was upregulated by fasting (9-fold increase in the liver; 3-fold increase in the spleen) regardless of LPS/PBS injection in both tissues (Fig. 4A and B), whereas SOCS-1 and SOCS-3 were significantly higher with fasting compared to the fed charr only in the spleen (1.4-fold increase; Fig. 3B) and liver (4-fold increase; Fig. 5A), respectively.

The fed and fasted charr differentially expressed their SOCS isoforms in response to LPS both temporally and in a tissue specific manner.There was a temporal increase in liver SOCS-1 in the control fed group at $96 \mathrm{~h}$ post-injection and this was not seen in the fasted group (Fig. 3A). In the spleen, fed charr showed elevated SOCS-1 levels in response to LPS at $96 \mathrm{~h}$ (Fig. 3B), while this change was not observed in the fasted charr (Fig. 3B). There was no interaction between LPS and fasting on liver SOCS-2 mRNA levels (Fig. 4A), whereas fasted charr showed lower spleen SOCS-2 mRNA levels in response to LPS at $96 \mathrm{~h}$ post-injection (Fig. 4B). LPS-injection significantly increased SOCS-3 mRNA levels in the liver and spleen of fed and fasted charr (see inset; Fig. 5A and B). There was a significant temporal reduction in spleen SOCS-3 mRNA levels in the control group at $96 \mathrm{~h}$ compared to $8 \mathrm{~h}$ post-injection in both the fed and fasted charr (Fig. 5B).
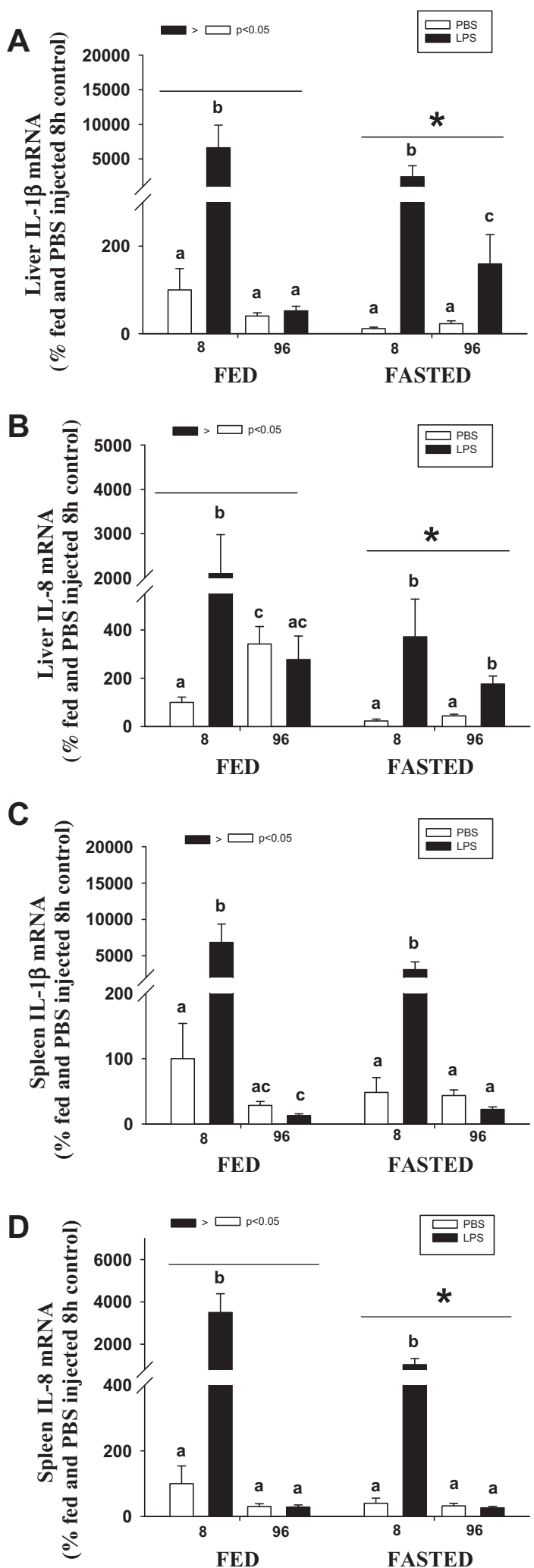

Fig. 1. Tissue-specific mRNA abundance of IL-1 $\beta$ (A and C) and IL-8 (B and D). Arctic charr that were either fed or fasted for 85 days were injected with LPS ( $2.5 \mathrm{mg} / \mathrm{kg}$ wt) or PBS. Liver (A and B) and spleen (C and D) were sampled 8 and 96 h postinjection. All values represent means \pm SEM $(n=5-6$ independent fish) relative to the value obtained for the fed fish injected with PBS and sampled at $8 \mathrm{~h}$ postinjection (100\%); bars with different letters are significantly different within the fed and fasted groups; * denotes fasted group significantly different from the fed group; the inset shows overall significant treatment (LPS vs PBS) effects (three-way ANOVA; $P<0.05)$ 

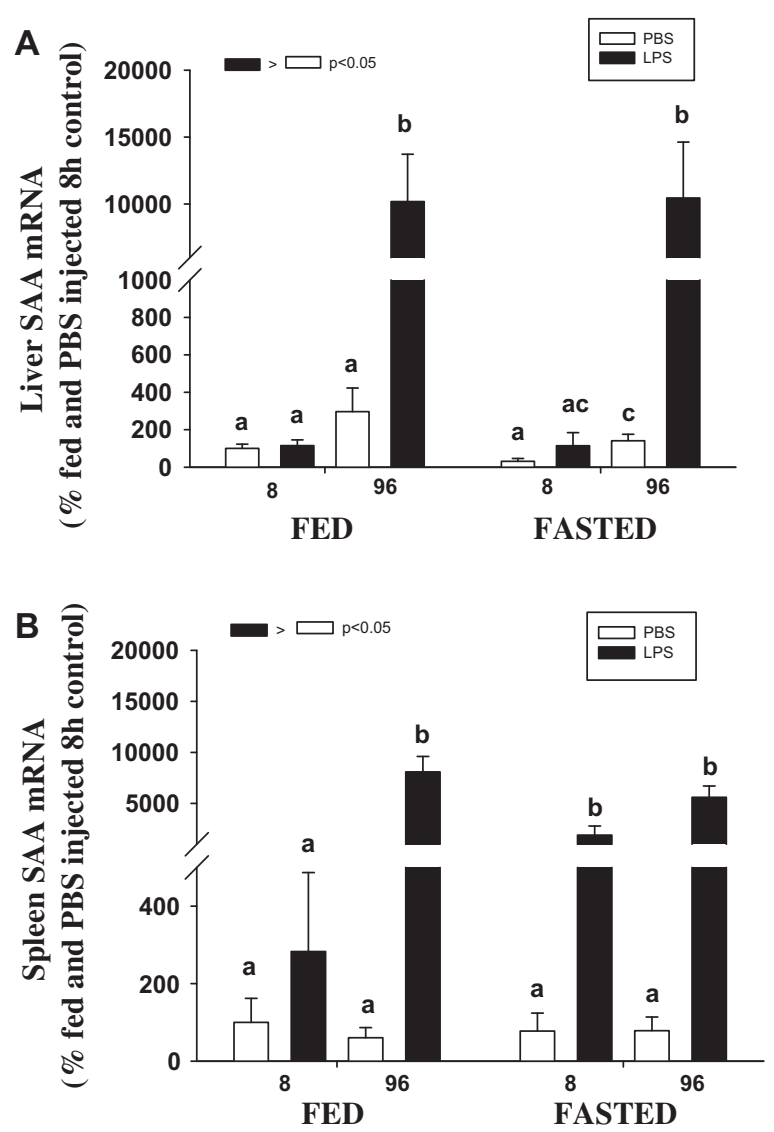

Fig. 2. Tissue-specific mRNA abundance of serum amyloid protein A (SAA). Arctic charr that were either fed or fasted for 85 days were injected with LPS $(2.5 \mathrm{mg} / \mathrm{kg}$ wt) or PBS. Liver (A) and spleen (B) were sampled 8 and $96 \mathrm{~h}$ post-injection. All values represent means \pm SEM ( $n=5-6$ independent fish) relative to the value obtained for the fed fish injected with PBS and sampled at $8 \mathrm{~h}$ post-injection (100\%); bars with different letters are significantly different within the fed and fasted groups; the inset shows overall significant treatment (LPS vs PBS) effects (threeway ANOVA; $P<0.05)$.

\section{Discussion}

High-latitude fish species have developed adaptive mechanisms that enable them to cope with the strong seasonality of the Arctic environment, including extended fasting and emaciation during the overwintering phase and intense feeding and energy deposition during the brief summer phase. We demonstrate that an emaciation comparable to that experienced by wild, anadromous Arctic charr during overwintering does not compromise their ability to evoke an immune response to LPS stimulation. This indicates that their immune competence is not compromised by long-term fasting and emaciation associated with this aspect of their life-history. Maintaining the immune competence may be essential for this species to fight infection, especially when they migrate back into the ocean in the summer. Our results show that extended fasting in this species upregulates SOCS-1, SOCS-2 and SOCS-3 mRNA levels in a tissue-specific manner. We hypothesize that upregulation of SOCS may be a key adaptive strategy to curtail energy demanding pathways, including growth hormone and cytokine signalling, during overwintering to metabolically cope with the extended fasting in this species.

\subsection{Innate immune modulation}

Cytokines and acute phase proteins are key mediators of the innate immune response and their expression is a key marker of
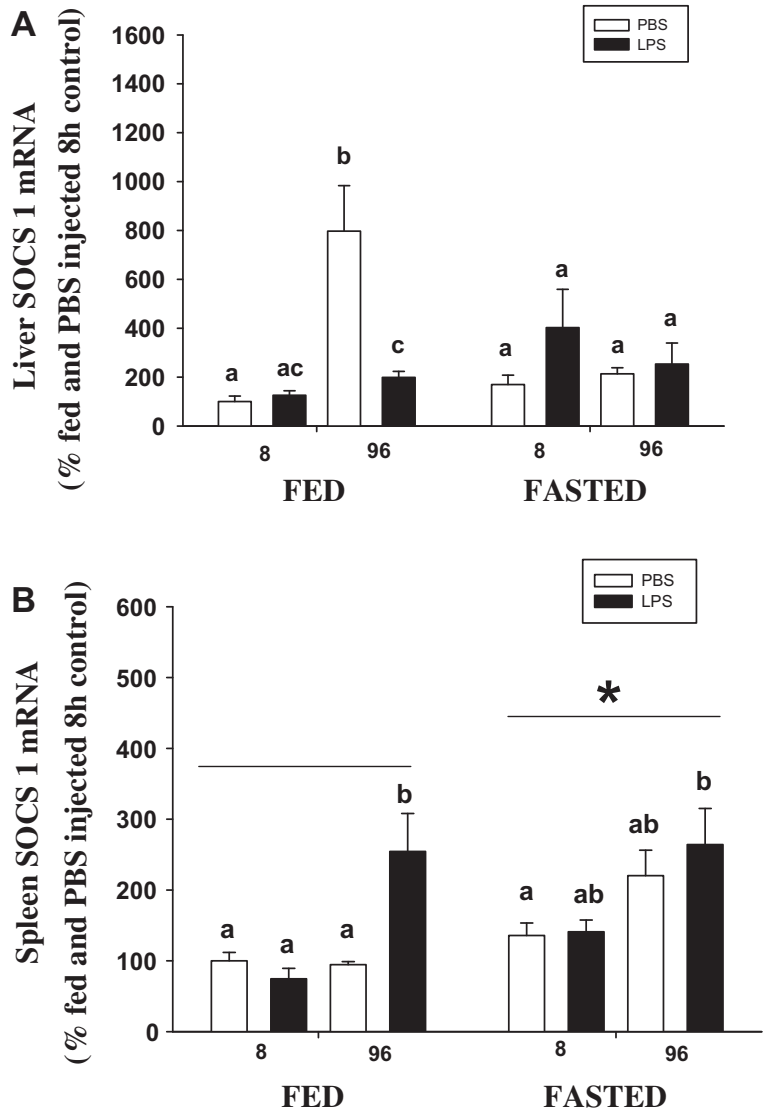

Fig. 3. Tissue-specific mRNA abundance of SOCS-1. Arctic charr that were either fed or fasted for 85 days were injected with LPS $(2.5 \mathrm{mg} / \mathrm{kg} \mathrm{wt})$ or PBS. Liver (A) and spleen (B) were sampled 8 and $96 \mathrm{~h}$ post-injection. All values represent means \pm SEM ( $n=5-6$ independent fish) relative to the value obtained for the fed fish injected with PBS and sampled at $8 \mathrm{~h}$ post-injection (100\%); bars with different letters are significantly different within the fed and fasted groups; ${ }^{*}$ denotes fasted group significantly different from the fed group (three-way ANOVA; $P<0.05$ ).

immune function (Engelsma, 2002). A key finding from this study was that LPS-mediated upregulation of cytokines, including IL-1 $\beta$ and IL- 8 were observed in both the fed and fasted Arctic charr. This is unlike other animal models where even short term starvation reduces the capacity for immune response activation (Martin et al., 2010). IL-1 $\beta$ is important in initiating inflammatory responses while IL-8 is a potent neutrophil chemotactic factor (Fast et al., 2007) and, together, they act as key mediators of innate immunity. However, the steady-state mRNA levels in fasted charr were lower than in the fed group and may be related to their negative energy balance. This is supported by the lower liver metabolic capacities associated with winter fasting (this study; Jørgensen et al., 2013) suggesting an overall metabolic suppression as an adaptation to extended fasting in these animals. Additionally, the absence of any difference in plasma cortisol and glucose levels between the fed and fasted charr supports the notion that these animals have unique metabolic adaptations to cope with the extreme seasonality without eliciting a stress response (Jørgensen et al., 2002) and attendant immune suppression.

There were tissue-specific differences in the temporal expression profiles of these cytokines due to extended fasting. Although liver is a non-classical immune tissue, unlike the spleen, we recently demonstrated that trout hepatocytes respond to LPS challenge by upregulating cytokine transcript levels (Philip et al., 2012). Our results confirm that liver also responds to immune challenges in Arctic charr. The transcript levels of LPS-stimulated IL-1 $\beta$ 

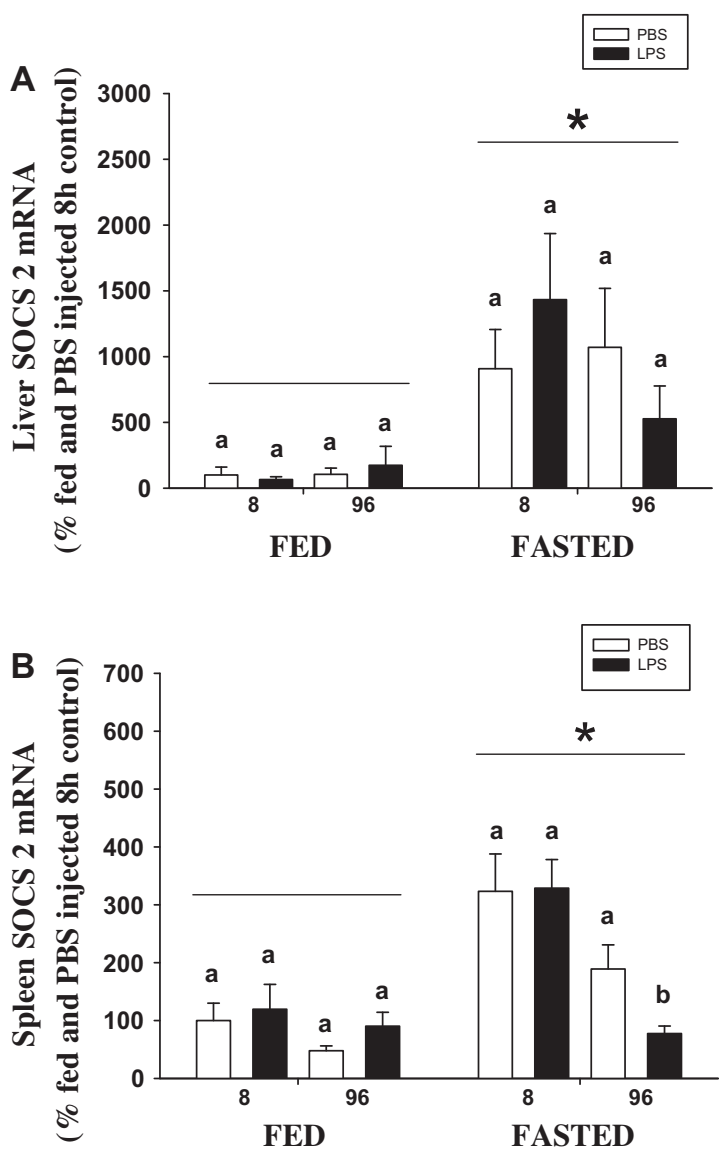

Fig. 4. Tissue-specific mRNA abundance of SOCS-2. Arctic charr that were either fed or fasted for 85 days were injected with LPS $(2.5 \mathrm{mg} / \mathrm{kg} w \mathrm{wt})$ or PBS. Liver (A) and spleen (B) were sampled 8 and $96 \mathrm{~h}$ post-injection. All values represent means \pm SEM ( $n=5-6$ independent fish) relative to the value obtained for the fed fish injected with PBS and sampled at $8 \mathrm{~h}$ post-injection (100\%); bars with different letters are significantly different within the fed and fasted groups; ${ }^{*}$ denotes fasted group significantly different from the fed group (three-way ANOVA; $P<0.05$ ).

and IL- 8 were back to the unstimulated steady-state levels by $96 \mathrm{~h}$ post-injection in the spleen but not the liver of fasted fish suggesting a tissue-specific difference in transcript dynamics. It remains to be seen if these changes were associated with enhanced mRNA stability in the liver or due to transcriptional activation. The temporal increase in liver IL-8 levels in the control fed group at $96 \mathrm{~h}$ postinjection may be due to the stress of handling and injection (Fast et al., 2007).

During an inflammatory response the liver synthesizes high levels of APPs that assists with the neutralization of invading pathogens (Martin et al., 2010). SAA is a positive APP, whose levels have been shown to increase during inflammation (Uhlar and Whitehead, 1999). Furthermore, the upregulation of SAA mRNA levels has been demonstrated in Arctic charr following infection with A. salmonicida (Jensen et al., 1997). Our results reveal that fasted charr also upregulate SAA transcript abundance in response to LPS challenge. In the liver of both fed and fasted charr, SAA mRNA abundance peaked at $96 \mathrm{~h}$ post-LPS injection with no significant change at $8 \mathrm{~h}$ post-injection. Given that cytokine expression occurred at $8 \mathrm{~h}$ after LPS injection compared to $96 \mathrm{~h}$ for SAA expression, and also because cytokines are the key stimulators of APP expression in the liver (Jensen and Whitehead, 1998), the delayed SAA response may be due to the kinetics of the response and the lag time associated with cytokine stimulation. The increased liver SAA expression seen in the control fasted fish at $96 \mathrm{~h}$ postinjection supports previous studies showing that fasted fish show
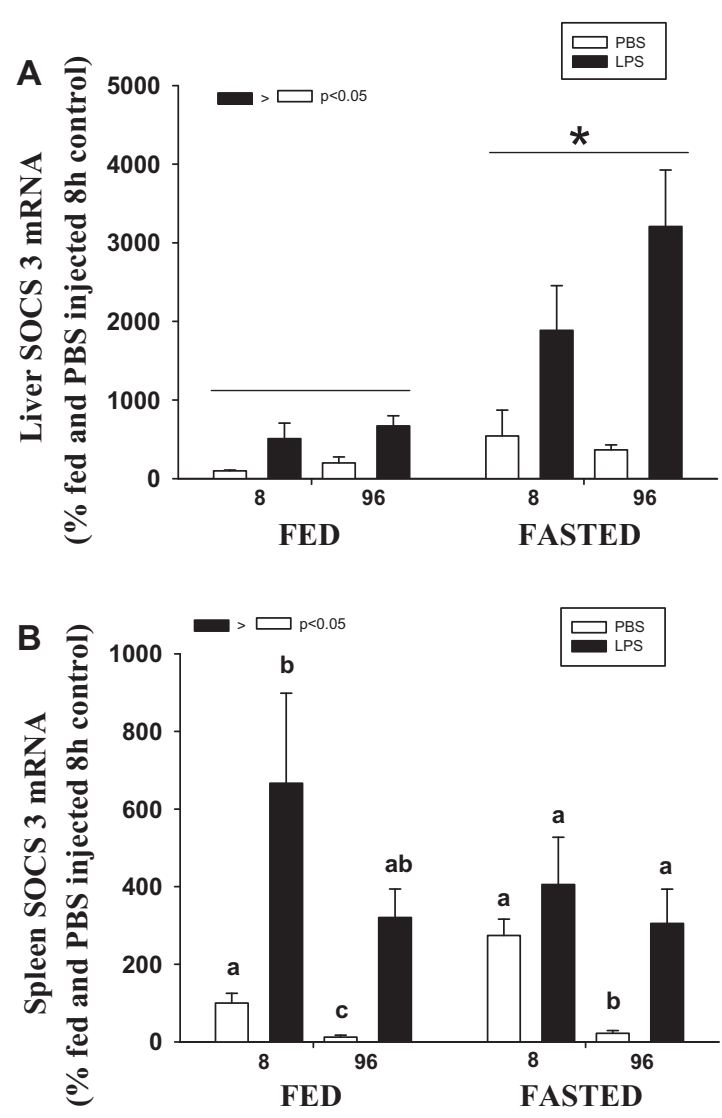

Fig. 5. Tissue-specific mRNA abundance of SOCS-3. Arctic charr that were either fed or fasted for 85 days were injected with LPS $(2.5 \mathrm{mg} / \mathrm{kg} \mathrm{wt})$ or PBS. Liver (A) and spleen (B) were sampled 8 and $96 \mathrm{~h}$ post-injection. All values represent means \pm SEM ( $n=4-6$ independent fish) relative to the value obtained for the fed fish injected with PBS and sampled at 8 h post-injection (100\%); bars with different letters are significantly different within the fed and fasted groups; ${ }^{*}$ denotes fasted group significantly different from the fed group; the inset shows overall significant treatment (LPS vs PBS) effects (three-way ANOVA; $P<0.05$ ).

a heightened acute phase response (Martin et al., 2010). Although acute phase proteins are synthesized predominantly in the liver (Talbot et al., 2009), our results show SAA expression profile to be similar in the spleen of fed charr in response to LPS stimulation. This is not surprising since recent studies have provided evidence of extrahepatic synthesis and cellular expression of APPs (Colten, 1992; Goetz et al., 2004; SaranyaRevathy et al., 2012). However, the faster SAA response to LPS stimulation in the spleen of fasted charr along with the cytokine response leads us to propose a paracrine and/or autocrine role for cytokines in APP response in this tissue. Although cytokines were upregulated by $8 \mathrm{~h}$ post-LPS injection in the fed group, the lack of a SAA response similar to that seen in the fasted fish suggests a potential interaction of nutritional status on APP response in charr.

\subsection{SOCS modulation}

While cytokines and APPs play an indispensable role in mediating immune and inflammatory responses in complex organisms, excessive cytokine signalling can be energy demanding and lead to chronic inflammation and disease (Shepherd et al., 2012). The SOCS genes act as key negative-regulators of cytokine signalling. Homologues of all the mammalian SOCS family members including SOCS-1, SOCS-2 and SOCS-3, have been identified in fish (Wang et al., 2011), but a functional role has not been thoroughly described yet. Our results reveal for the first time that fasted Arctic 
charr increase the expression of SOCS genes in a tissue specific manner. The results confirm the recent finding that emaciation per se increases the expression of liver SOCS-2 and SOCS-3 in Arctic charr (Jørgensen et al., 2013). Also, fasting in this species increases the mRNA abundance of SOCS- 1 and SOCS-2 in the spleen. This corresponds with the lower levels of cytokine expression that we observed in the fasted fish. As SOCS genes are involved in attenuating the inflammatory response to cytokines in animals, including fish (Martin et al., 2010; Zhu et al., 2012), we propose that during conditions of extended fasting, this might be a key adaptation to protect against energy demanding processes, including excessive cytokine signalling.

Our results indicate that SOCS expression in response to LPS stimulation is also tissue-specific. While LPS upregulated liver and spleen SOCS-3 transcript levels, it did not alter SOCS-1 and SOCS-2 mRNA levels in the liver. In the spleen of fed charr, it was seen that LPS increasd SOCS-1 expression over time while in the spleen of fasted charr, LPS decreased SOCS-2 expression over time suggesting a potential interaction of nutritional status on LPS-mediated SOCS responses in charr. Together, this supports previous studies suggesting transient expression of SOCS genes in a species-, tissue- and isoform-specific manner in fish in response to LPS stimulation (Philip et al., 2012; Shepherd et al., 2012). The reason for the temporal increase in liver SOCS-1in the control fed group at $96 \mathrm{~h}$ post-injection or the temporal reduction in spleen SOCS-3 levels in the control fed and fasted groups at $96 \mathrm{~h}$ postinjection is not known. We cannot rule out the possibility that the stress of handling and injection may be modulating SOCS expression (Shepherd et al., 2012; Wang et al., 2010), but this warrants further investigation.

Although most SOCS proteins are induced by cytokines, they have also been shown to be induced by various other stimuli, such as pathogen associated molecular patterns (PAMPs), and bacterial, viral, and parasitic infection (Akhtar and Benveniste, 2011). We recently showed the SOCS genes to be responsive to cortisol, the major stress hormone in fish, which highlights the role played by the SOCS genes in integrating different physiological responses (Philip et al., 2012). Additionally, it has also been shown that SOCS proteins interact with GH receptor signalling (Wang et al., 2011). Fish growth is a complex function mostly regulated by the growth hormone (GH)/insulin-like growth factor (IGF) system (Gabillard et al., 2006). Over-expression of SOCS-2 has been shown to interfere with the JAK2-STAT5b pathway and inhibit growth hormone signalling (Croker et al., 2008). Moreover homozygote GH-transgenic zebrafish who express double the amount of GH compared with hemizygote individuals, also express higher levels of SOCS-1 and SOCS-3 and display slower growth rates (Studzinski et al., 2009). The increased SOCS expression that we observed with fasting, especially SOCS-2 which was increased both in the liver and spleen, correlates well with the reduced body weight of the fasted charr and the reduced hepatic IGF-1 levels, marker of GH signalling, suggesting inhibition of GH signalling (Jørgensen et al., 2013). Consequently, the heightened expression of SOCS genes with extended fasting in Arctic charr may be an adaptative strategy restricting energy demanding processes, including growth and immune responses, to offset the reduced substrate availability during overwintering.

In summary, extended fasting and emaciation did not deter the capacity to elicit an innate immune response to LPS challenge in the anadromous Arctic charr. This supports our previous finding that resistence toward furunculosis was not compromised by extended fasting in Arctic charr (Maule et al., 2005). This is a unique adaptation as even short-term fasting in animals, including mammals and fish, reduced the capacity for immune response activation (Wing et al., 1988; Pires et al., 2007; Caruso et al., 2011; Martin et al., 2010).We propose that maintenance of immune competence in Arctic charr despite extended fasting as an adaptive trait that arose along with their anadromous life-strategy, preparing the emaciated animals to defend against pathogenic challenges when they migrate from fresh water to seawater. A key finding was that extended fasting upregulated SOCS transcript levels in Arctic charr. As negative regulators of cytokine and growth hormone signalling, the upregulation of SOCS by fasting may be a key strategy during overwintering to conserve or limit energy substrate utilization by suppressing energy demanding pathways, including growth hormone and cytokine signalling. While the factor(s) involved in SOCS upregulation with fasting is unclear and warrants further investigation, we propose a key role for the SOCS in the energy substrate repartitoning to cope with the extended fasting in Arctic charr.

\section{Acknowledgements}

This study was supported by the Tromsø Research Foundation, University of Tromsø, Norway and the Natural Sciences and Engineering Research Council of Canada Discovery Grant.

\section{References}

Akhtar, L.N., Benveniste, E.N., 2011. Viral exploitation of host SOCS protein functions. J. Virol. 85, 1912e21.

Aluru, N., Leatherland, J.F., Vijayan, M.M., 2010. Bisphenol A in oocytes leads to growth suppression and altered stress performance in juvenile rainbow trout. PLoS One 5, e10741.

Berczi, I., 1986. The influence of the pituitary-adrenal axis on the immune system. In: Pituitary Function and Immunity. CRC Press, Boca Raton (FL), pp. 49-133.

Caruso, G., Denaro, M.G., Caruso, R., Mancari, F., Genovese, L., Maricchiolo, G., 2011. Response to short term starvation on growth, haematological, biochemical and non-specific immune parameters in European sea bass (Dicentrarchus labrax) and blackspot sea bream (Pagellus bogaraveo). Marine Environ. Res. 72, 46-52.

Colten, H.R., 1992. Tissue-specific regulation of inflammation. J. Appl. Physiol. 72, 1 7.

Croker, B.A., Kiu, H., Nicholson, S.E., 2008. SOCS regulation of the JAK/STAT signalling pathway. Semin. Cell Dev. Biol. 19, 414-422.

Engelsma, M.Y., 2002. Neuroendocrine-immune interactions in fish: a role for interleukin-1. Vet. Immunol. Immunopathol. 87, 467-479.

Fast, M.D., Johnson, S.C., Jones, S.R.M., 2007. Differential expression of the proinflammatory cytokines IL-1 $\beta-1, T N F \alpha-1$ and IL- 8 in vaccinated pink (Oncorhynchus gorbuscha) and chum (Oncorhynchus keta) salmon juveniles. Fish Shellfish Immunol. 22, 403-407.

Frøiland, E., Murashita, K., Jørgensen, E.H., Kurokawa, T., 2010. Leptin and ghrelin in anadromous Arctic charr: cloning and change in expressions during a seasonal feeding cycle. Gen. Comp. Endocrinol. 165, 136-143.

Gabillard, J.C., Kamangar, B.B., Montserrat, N., 2006. Coordinated regulation of the GH/IGF system genes during refeeding in rainbow trout (Oncorhynchus mykiss). J. Endocrinol. 191, 15-24.

Goetz, F.W., Iliev, D.B., McCauley, L.A., Liarte, C.Q., Tort, L.B., Planas, J.V., Mackenzie, S., 2004. Analysis of genes isolated from lipopolysaccharide-stimulated rainbow trout (Oncorhynchus mykiss) macrophages. Mol. Immunol. 41, 1199-1210.

Houston, A.I., McNamara, J.M., Barta, Z., Klasing, K.C., 2007. The effect of energy reserves and food availability on optimal immune defence. Proc. Biol. Sci. Royal Soc. 274, 2835-2842.

Jensen, L.E., Hiney, M.P., Shields, D.C., Uhlar, C.M., Lindsay, A.J., Whitehead, A.S., 1997. Acute phase proteins in salmonids: evolutionary analyses and acute phase response. J. Immunol. 158, 384-392.

Jensen, L.E., Whitehead, A.S., 1998. Regulation of serum amyloid A protein expression during the acute-phase response. Biochem. J. 334, 489-503.

Jørgensen, E.H., Martinsen, M., Strøm, V., Hansen, K.E.R., Ravuri, C.S., Gong, N., Jobling, M., 2013. Long-term fasting in the anadromous Arctic charr is associated with downregulation of metabolic enzyme activity and upregulation of leptin A1 and SOCS expression in the liver. J. Exp. Biol. 216, 3222-3230.

Jørgensen, E.H., Johansen, S.J.S., Jobling, M., 1997. Seasonal pattern of growth, lipid deposition and lipid depletion in anadromous Arctic charr. J. Fish Biol. 51, 312 326.

Jørgensen, E.H., Vijayan, M.M., Aluru, N., Maule, A.G., 2002. Fasting modifies Aroclor 1254 impact on plasma cortisol, glucose and lactate responses to a handling disturbance in Arctic charr. Comparative biochemistry and physiology. Toxicol. Pharmacol. CBP 132, 235-245.

Keppler, D., Decker, K., 1974. Glycogen determination with amyloglucosidase. In: Methods of Enzymatic Analysis. Academic Press, New York, pp. 1127-1131.

Kile, B.T., Alexander, W.S., 2001. The suppressors of cytokine signalling (SOCS). Cell. Mol. Life Sci. 58, 1627-1635.

MacKenzie, S., Iliev, D., Liarte, C., Koskinen, H., Planas, J.V., Goetz, F.W., Mölsä, H., Krasnov, A., Tort, L., 2006. Transcriptional analysis of LPS-stimulated activation 
of trout (Oncorhynchus mykiss) monocyte/macrophage cells in primary culture treated with cortisol. Mol. Immunol. 43, 1340-1348.

Martin, S.A.M., Douglas, A., Houlihan, D.F., Secombes, C.J., 2010. Starvation alters the liver transcriptome of the innate immune response in Atlantic salmon (Salmo salar). BMC Genomics 11, 418.

Maule, A.G., Jørgensen, E.H., Vijayan, M.M., Killie, J.E.A., 2005. Aroclor 1254 exposure reduces disease resistence and innate immune responses in fasted Arctic charr. Environ. Toxicol. Chem. 24, 117-124.

Morera, D., Roher, N., Ribas, L., Balasch, J.C., Donate, C., et al., 2011. RNA-Seq reveals an integrated immune response in nucleated erythrocytes. PLoS One 6 (10), e26998.

O'Sullivan, L.A., Noor, S.M., Trengove, M.C., Lewis, R.S., Liongue, C., Sprigg, N.S., Nicholson, S.E., Ward, A.C., 2011. Suppressor of cytokine signaling 1 regulates embryonic myelopoiesis independently of its effects on T cell development. J. Immunol. 186, 4751-4761.

Philip, A.M., Daniel Kim, S., Vijayan, M.M., 2012. Cortisol modulates the expression of cytokines and suppressors of cytokine signalling (SOCS) in rainbow trout hepatocytes. Dev. Comp. Immunol. 38, 360-367.

Pires, J., Curi, R., Otton, R., 2007. Induction of apoptosis in rat lymphocytes by starvation. Clin. Sci. 112, 59-67.

SaranyaRevathy, K., Umasuthan, N., Whang, I., Lee, Y., Lee, S., Oh, M.J., Jung, S.J., Choi, C.Y., Park, C.J., Park, H.C., Lee, J., 2012. A novel acute phase reactant, serum amyloid A-like 1, from Oplegnathus fasciatus: genomic and molecular characterization and transcriptional expression analysis. Dev. Comp. Immunol. 37, 294-305.

Shepherd, B.S., Rees, C.B., Binkowski, F.P. Goetz, F.W. 2012 Characterization and evaluation of sex-specific expression of suppressors of cytokine signaling (SOCS)-1 and -3 in juvenile yellow perch (Perca flavescens) treated with lipopolysaccharide. Fish Shellfish Immunol. 33, 468-481.

Sigh, J., Lindenstrøm, T., Buchmann, K., 2004. Expression of pro-inflammatory cytokines in rainbow trout (Oncorhynchus mykiss) during an infection with Ichthyophthirius multifiliis. Fish Shellfish Immunol. 17, 75-86.

Siikavuopio, S.I., Knudsen, R., Winger, A.C., Kristoffersen, R., 2009. Is the winter period a severe bottleneck of anadromous riverine Arctic charr parr? Ecol. Freshw. Fish 18, 126-131.

Steel, D.M., Whitehead, A.S., 1994. The major acute phase reactants: C-reactive protein, serum amyloid P component and serum amyloid A protein. Immunol. Today $15,81-88$.

Stolte, E.H., Nabuurs, S.B., Bury, N.R., Sturm, A., Flik, G., Savelkoul, H.F.J., LidyVerburg-van Kemenade, B.M., 2008. Stress and innate immunity in carp: corticosteroid receptors and pro-inflammatory cytokines. Mol. Immunol. 46, 70-79.
Studzinski, A.L.M., Almeida, D.V., Lanes, C.F.C., Figueiredo, M.D.A., Marins, L.F., 2009 SOCS1 and SOCS3 are the main negative modulators of the somatotrophic axis in liver of homozygous GH-transgenic zebrafish (Danio rerio). Gen. Comp. Endocrinol. 161, 67-72.

Sun, D.X. Muthukumar, A.R., Lawrence, R.A.,Fernandes, G, 2001. Effects of calorie restriction on polymicrobial peritonitis induced by cecum ligation and puncture in young C57BL/6 mice. Clin. Diagn. Lab. Immunol. 8, 1003-1011.

Talbot, A.T., Pottinger, T.G., Smith, T.J., Cairns, M.T., 2009. Acute phase gene expression in rainbow trout (Oncorhynchus mykiss) after exposure to a confinement stressor: a comparison of pooled and individual data. Fish Shellfish Immunol. 27, 309-317.

Tveiten, H., Bjørn, P.A., Johnsen, H.K., Finstad, B., McKinley, R.S., 2010. Effects of the sea louse Lepeophtheirus salmonis on temporal changes in cortisol, sex steroids, growth and reproductive investment in Arctic charr Salvelinus alpinus. J. Fish Biol. 76, 2318-2341.

Tveiten, H., Johnsen, H.K., Jobling, M., 1996. Influence of maturity status on the annual cycles of feeding and growth in Arctic charr reared at constant temperature. J. Fish Biol. 48, 910-924.

Uhlar, C.M., Whitehead, A.S., 1999. Serum amyloid A, the major vertebrate acute phase reactant. Eur. J. Biochem. 265, 501-523.

Walrand, S., Moreau, K., Caldefie, F., Tridon, A., Chassagne, J., Portefaix, G., Cynober, L., Beaufrere, B., Vasson, M.P., Boirie, Y., 2001. Specific and nonspecific immune responses to fasting and refeeding differ in healthy young adult and elderly persons. Am. J. Clin. Nutr. 74, 670-678.

Wang, T., Gao, Q., Nie, P., Secombes, C.J., 2010. Identification of suppressor of cytokine signaling (SOCS) 6, 7,9 and CISH in rainbow trout Oncorhynchus mykiss and analysis of their expression in relation to other known trout SOCS. Fish Shellfish Immunol. 29, 656-667.

Wang, T., Gorgoglione, B., Maehr, T., Holland, J.W., Vecino, J.L.G., Wadsworth, S. Secombes, C.J., 2011. Fish suppressors of cytokine signaling (SOCS): gene discovery, modulation of expression and function. J. Signal Transduct. http:// dx.doi.org/10.1155/2011/905813.

Wang, T., Secombes, C.J., 2008. Rainbow trout suppressor of cytokine signalling (SOCS)-1, 2 and 3: molecular identification, expression and modulation. Mol Immunol. 45, 1449-1457.

Wing, E.J., Magee, D.M., Barczynski, L.K., 1988. Acute starvation in mice reduces the number of $\mathrm{T}$ cells and suppresses the development of T-cell-mediated immunity. Immunology 63, 677-682.

Zhu, L.Y., Nie, L., Zhu, G., Xiang, L.X., Shao, J.Z., 2012. Advances in research of fish immune-relevant genes: a comparative overview of innate and adaptive immunity in teleosts. Dev. Comp. Immunol. 39, 39-62. 